\title{
Commentary: The appendage strikes back: The last surgeon
}

\author{
Francis Wellens, MD, and Mark La Meir, MD, PhD
}

\author{
From the Department of Cardiac Surgery, UZ Brussel, Brussels, Belgium. \\ Disclosures: M.L.M. is a consultant for AtriCure Inc, and reports speaker fees from Medtronic (Minneapolis, \\ Minn). F.W. has nothing to disclose with regard to commercial support. \\ Received for publication Oct 7, 2018; accepted for publication Oct 8, 2018; available ahead of print Nov 7, 2018. \\ Address for reprints: Francis Wellens, MD, Department of Cardiac Surgery, UZ Brussel, Brussels, Belgium \\ (E-mail: fl.wellens@gmail.com). \\ J Thorac Cardiovasc Surg 2019;158:e13-4 \\ $0022-5223 / \$ 36.00$ \\ Copyright $(2018$ by The American Association for Thoracic Surgery \\ https://doi.org/10.1016/j.jtcvs.2018.10.026
}

In this case report, Wehbe and colleagues ${ }^{1}$ describe 2 fatal bleeding complications after left atrial appendage (LAA) exclusion due to postprocedure myocardial tearing at the site of exclusion. Because the denominator is not specified, it is not clear what the statistic value of this number is.

Most patients undergoing concomitant or stand-alone surgical atrial fibrillation treatment will have their LAA addressed. Although widely performed, several studies have raised significant concerns regarding classic surgical techniques for LAA closure. In the original maze procedure, LAA obliteration is described as an excision with suture closure. More recently, surgical exclusion of the LAA can be achieved endocardially or epicardially by over-sewing, excision, ligation, stapling, or application of a clip system (AtriClip, AtriCure Inc, Mason, Ohio).

Kanderian and colleagues ${ }^{2}$ assessed long-term surgical LAA closure in a total of 137 of 2546 patients with transesophageal echocardiography. The transesophageal echocardiography measurements included color Doppler flow in the LAA and interrogation for thrombus. Patent LAA, remnant LAA (residual stump $>1 \mathrm{~cm}$ ), and excluded LAA with persistent flow into the LAA were identified as unsuccessful closure. Of the 137 patients, $52(38 \%)$ underwent excision and $85(62 \%)$ underwent exclusion (73 suture and 12 stapler). Only 55 of 137 closures (40\%) were successful.

Lee and colleagues ${ }^{3}$ compared in a randomized, prospective pilot study 3 atrial appendage elimination techniques: internal ligation, stapled excision, and surgical excision. Failure of LAA occlusion was defined as above. The overall failure rate was $57 \%$. There were no major complications.

The single-center, randomized Left Atrial Appendage Occlusion Study of 77 patients undergoing concurrent coronary artery bypass grafting showed that occlusion of the LAA by suture or stapling without amputation was incomplete in $44 \%$ of cases.

Also, catheter-based percutaneous LAA occlusion fatal complications have been reported. Boersma and colleagues ${ }^{5}$ reported the periprocedural outcomes of up to

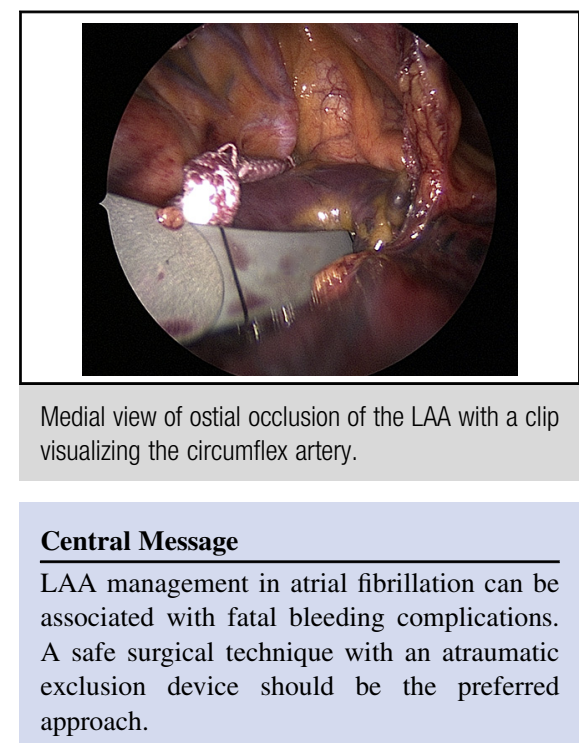

See Article page e207 in the December 2018 issue.

30 days after LAA closure with the Watchman device. The overall 30 -day mortality rate was $0.7 \%$.

Ailawadi and colleagues ${ }^{6}$ demonstrated in 70 patients that atraumatic exclusion of the LAA can be performed during open cardiac surgery with the AtriClip device. There were no instances of damage to the appendage, circumflex artery, or pulmonary artery intraoperatively. None of the patients had bleeding from the appendage, and no additional repair sutures were required. During follow-up, no patient showed any clinical evidence of complication from the AtriClip device. Furthermore, epicardial LAA clip occlusion electrically isolates the LAA and could therefore reduce the recurrence of atrial fibrillation. ${ }^{7}$

Whether the reason for failure of occlusion or bleeding is associated with the surgical technique, the frailty of the atrial tissue or both is difficult to decide, but is solely dependent on the surgeon's judging abilities. Because the LAA should be treated with our uttermost respect, an atraumatic exclusion technique could facilitate the decision making. We strongly believe this should be the method of choice in open and closed access.

This report makes a compelling case that although health care funding remains limited, the increased budget impact with an LAA occlusion device could well be accepted to improve safety and efficacy. 


\section{References}

1. Wehbe MS, Doll N, Merk DR. Fatal complications associated with surgical left atrial appendage exclusion. J Thorac Cardiovasc Surg. 2018;156:e207-8.

2. Kanderian AS, Gillinov AM, Pettersson GB, Blackstone E, Klein AL. Success of surgical left atrial appendage closure: assessment by transesophageal echocardiography. J Am Coll Cardiol. 2008;52:924-9.

3. Lee R, Vassallo P, Kruse J, Malaisrie SC, Rigolin V, Andrei AC, et al. A randomized, prospective pilot comparison of 3 atrial appendage elimination techniques: internal ligation, stapled excision, and surgical excision. J Thorac Cardiovasc Surg. 2016;152:1075-80.

4. Healey JS, Crystal E, Lamy A, Teoh K, Semelhago L, Hohnloser SH, et al. Left atrial appendage occlusion study (LAAOS): results of a randomized controlled pilot study of left atrial appendage occlusion during coronary bypass surgery in patients at risk for stroke. Am Heart J. 2005;150:288-93.

5. Boersma C, Schmidt B, Betts TR, Sievert H, Tamburino C, Teiger E, et al; EWOLUTION investigators. Implant success and safety of left atrial appendage closure with the WATCHMAN device: peri-procedural outcomes from the EWOLUTION registry. Eur Heart J. 2016;37:2465-74.

6. Ailawadi G, Gerdisch MW, Harvey RL, Hooker RL, Damiano RJ Jr, Salamon T, et al. Exclusion of the left atrial appendage with a novel device: early results of a multicenter trial. J Thorac Cardiovasc Surg. 2011;142:1002-9.

7. Starck CT, Steffel J, Emmert MY, Plass A, Mahapatra S, Falk V, et al. Epicardial left atrial appendage clip occlusion also provides the electrical isolation of the left atrial appendage. Interact Cardiovasc Thorac Surg. 2012;15:416-8. 